\title{
The impact of phase II of the EU ETS on wholesale electricity prices
}

\author{
Ibrahim AHAMADA * and Djamel KIRAT ${ }^{\dagger \ddagger}$
}

September 6, 2012

\begin{abstract}
This paper addresses the economic impact of the European Union Emission Trading Scheme (EU ETS) for carbon on wholesale electricity prices in France and Germany during the Kyoto commitment period (2008-2012). We identify a structural break occurred on the carbon spot price series on October 2008, which is mainly resulting from the financial and economic crisis. We find that the price of carbon does not matter for electricity prices in either countries before October 2008. After October 2008, electricity producers in both countries were constrained to include the carbon price in their cost functions. During that period, French electricity producers were more constrained than their German counterparts. To apply for the same abatement effort to electricity producers of different European countries, even with heterogeneous energy mixes, we propose simply to adjust the ceiling of carbon permits granted to each of them.
\end{abstract}

Keywords: Carbon Emission Trading, Multivariate GARCH models, Structural breaks, Energy prices. JEL classification: C14, C32, C51, Q49, Q58

\section{Introduction}

To implement the Kyoto Protocol, the European authorities established the European Union Emissions Trading Scheme (EU ETS). This is the world's largest emissions permit market to date and covers almost half of the European Union's total carbon dioxide emissions. It has been first organized in two phases: Phase

\footnotetext{
${ }^{*}$ Centre d'Economie de la Sorbonne, Paris School of Economics, University Paris1 Pantheon-Sorbonne. Address: 106-112 boulevard de l'hôpital 75013 Paris, France. Phone : 331440783 50. Email: ahamada@univparis1.fr.

${ }^{\dagger}$ Centre d'Economie de la Sorbonne, Paris School of Economics, University Paris1 Pantheon-Sorbonne. Address: 106-112 boulevard de l'hôpital 75013 Paris, France. Phone : 33144078190 . Email: djamel.kirat@univparis1.fr.

${ }^{\ddagger}$ We would like to thank Katheline Schubert and Natacha Raffin for their helpful discussions and comments. We also thank discussants and participants in the "Friday Lunch Meeting" at the Chaire Economie du Climat held on November 18 th, 2011.
} 
1, from January 1st, 2005 to December 31th, 2007; and phase 2 ranging from January 1st, 2008 to December 31th, 2012. Phase 1 is considered as a pilot phase before phase 2, which coincides with the Kyoto protocol's first commitment period. A third phase was formalized in January 2008 that will start in 2013 last until 2020. The market is based on a "cap and trade" mechanism. Market players receive free annual carbon-emission permits at the beginning of the year. They then fulfil their commitment by providing permits corresponding to the tons of $\mathrm{CO} 2$ they have emitted by the end of the year. Those that have emitted more $\mathrm{CO} 2$ than their allocation comply by buying more permits on the market. There is a penalty for noncompliance of $40 €$ in phase I and $100 €$ in phase 2 for every ton of emitted CO2 for which firms do not surrender an allowance; in addition, they have to surrender the missing allowances in the following year.

The pilot phase of the EU ETS was distinguished by restrictions on banking and borrowing CO2-emission permits to or from phase 2. Pilot phase allowances could not be banked into the second phase and lost their value if unused for compliance, making this phase a self-contained market that is not related to future caps and political decisions regarding Kyoto. Conversely, banking from the second into latter phases is permitted. Thus, the main contributions of the second phase of the EU ETS are the possibility of "banking" for subsequent periods and the reduction of allowance caps. At European level, the allowances fell by $6.5 \%$. In Germany and France, the decrease reach nearly $10 \%$ and 15\%, respectively.

The EU ETS is mainly concerned with energy ${ }^{1}$ and the major emitters of the industrial sector. It is dominated by firms involved in electricity generation. Its main objective is to encourage the industry's biggest emitters to reduce their carbon emissions and invest in clean technologies. Achieving this objective relies on a real carbon price signal inducing electricity producers to make long-run choices to produce electricity with fewer emissions. The price of electricity is determined by the cost of fossil fuels, the impact of environmental policies, and climatic factors (such as temperature and rainfall). Economic theory suggests that the carbon price is a marginal cost and that the opportunity cost of the carbon permit equals its market price. As such, the carbon price should be reflected in the price of electricity. In this context, the ex-post empirical analysis of the impact of the European market for $\mathrm{CO} 2$ permits on electricity markets is essential for the assessment of the efficiency and consequences of the EU ETS.

There has been a considerable work on the impact of the EU ETS, during its pilot phase, on electricity prices in various European markets. Sijm et al. $(2005,2006)$ use OLS to determine the fraction of the carbon price reflected in electricity prices in Holland and Germany. Honkatukia et al. (2008) consider the long- and short-run dynamics of electricity, gas and coal prices and the price of carbon permits in the Finnish market using a VAR analysis. Bunn and Fezzi (2008) use a vector error correction model with allowances, electricity and gas prices in the United Kingdom (UK), and daily temperatures in London and seasonal dummies as exogenous variables. They carried out a structural analysis through imposing shortrun identifying restrictions based on auxiliary regressions. They find that the UK gas price influences the allowance price, and that both gas and carbon prices help determine the electricity price. Kirat and Ahamada

\footnotetext{
${ }^{1}$ Oil refining, electricity production, heating and gas transportation.
} 
(2011) study the impact of carbon trading on the French and German electricity markets together taking the heterogeneity of national energy mixes into account. After identifying different sub-periods of the EU ETS during its pilot phase, they estimate an empirical time-series model based on electricity-generation cost functions including the cost of carbon. They model the prices of various electricity contracts in France and Germany and look at the volatility of electricity prices around their fundamentals while evaluating the correlation between electricity prices in the two countries. They find that electricity producers in both countries were constrained to include the carbon price in their cost functions during the first two years of the EU ETS. Over this period, German electricity producers were more constrained than their French counterparts, and the inclusion of the carbon price in the electricity-generation cost function was much more stable in Germany than in France. They also find evidence of fuel switching in electricity generation in Germany after the collapse of the carbon market. They claim that electricity prices in both countries were more strongly correlated before than after the collapse of the carbon market during the pilot phase. They conclude that the European market for emission allowances has greatly contributed to the partial alignment of the wholesale price of electricity in France to that in Germany. Our major contribution is the study of the impact of carbon trading on electricity prices with the EU ETS data for CO2 emissions during phase 2.

As an extension of the article by Kirat and Ahamada (2011), we examine whether and to what extent the allowance price during the second phase of the EU ETS is included in the cost function of electricity generation, taking the heterogeneity of national energy mixes into account. In particular, we focus on France and Germany. We deal with the volatility of the electricity price around its fundamentals. We set up an empirical model that specifies electricity prices as a function of a set of widely accepted prices drivers (fuel prices, temperature, allowance price). The estimation methodology allows us to measure the instantaneous correlation between the wholesale electricity prices across the two countries. We cover the second phase of the EU ETS until December 2010 and take into account different sub-periods: before and after October 2008. This corresponds to a structural break occurred on the carbon spot price series, which is mainly resulting from the financial and economic crisis. We then compare the results with those of the first phase of the EU ETS reported by Kirat and Ahamada (2011) in order to evaluate improvements of phase 2: mainly, the possibility of banking permits to future periods and the reduction of the cap representing the total amount of allowances.

The paper is organized as follows. Section 2 presents the functioning of the electricity sector. Section 3 presents a descriptive analysis of the data and describes the econometric modelling. Section 4 presents the results and their interpretation, and Section 5 concludes.

\section{The electricity-generation sector}

The electricity sector received a large share of the Community $\mathrm{CO} 2$ permit allocation in both phases of the European market. Despite this, it was the only sector with a net shortage of allowances during phase 
I of the EU ETS, whereas all other sectors acted as net allowance suppliers. Before analyzing the impact of carbon constraints, it is probably useful to describe how the sector is organized. There are four main areas: production, transportation, distribution and marketing. There are also purely financial activities such as brokerage and trading (over the counter or on power exchanges). Electricity generation is the main polluting activity and since 1998 has been opened up to competition in the process of liberalizing the European electricity market. Electricity is produced from various primary energy sources: nuclear, coal, oil, gas, hydropower, biomass, wind, solar and geothermal power. The share of each of these describes the energy-source mix in electricity generation. This mix differs sharply from one European country to another due to differences in energy policies and the particular geographical and geological features of each country. For instance, while in Germany more than $50 \%$ of electricity is generated using coal and lignite, France produces almost $80 \%$ of its electricity from nuclear energy, with fossil fuels accounting for just $9 \%$. Knowing that producing electricity from fossil fuel plants is more costly and emits more $\mathrm{CO} 2$ compared to nuclear plants, one could expect that electricity and carbon prices relationships might differ in both countries.

Electricity differs from other goods as it is not storable, which explains some of the particular characteristics of the generation sector described below. There are considerable fluctuations in electricity demand from one hour, day and season to another. Continuous adaptation of electricity supply is thus required to meet demand. The cost of electricity production differs according to the primary energy source used, and therefore so does profitability. Consequently, electricity production is characterized by the sequential use of production technologies depending on production costs. Producers start up power plants to meet demand, in increasing order of their variable marginal costs of production. This is the concept of "merit order" between different technologies which is determined by the variable marginal cost of production (where variable costs refer to fuel and operational costs). This merit order between technologies is not fixed and depends on carbon price. To that respect, the switching price was thus defined by Sijm et al. (2005) as the price of carbon at which it becomes more profitable for a producer to use a gas power plant rather than a coal plant.

The choice of power production plans does not depend only on the merit order, but also on technical parameters such as the number of functioning hours necessary for the profitability of a given type of plant, the depreciation of fixed capital invested in different plants, and the availability of the Kwh produced. ${ }^{2}$

The EU ETS stipulates that the percentage of reductions for each installation in a country is "grandfathered". There is therefore an obligation to reduce annual $\mathrm{CO} 2$ emissions and thus, throughout the European Union, a supply function of CO2-emission reduction (Bunn and Fezzi, 2008) reflecting the increasing marginal costs of reducing emissions over a year. In the electricity-generation sector, this supply function reflects changes in the merit order curve between the primary energies. As these changes depend on the energy mixes

\footnotetext{
${ }^{2}$ Electricity producers make complex calculations of production costs of different technologies while ensuring that production follows real-time demand. In peak periods, a number of production units are used, and as demand falls so does the number of production units. This implies stopping and restarting units depending on demand. The operational features of the production units (including start-up time, the levels of maximum and minimum production, and energy efficiency) imply that power plants may be used continuously or discontinuously.
} 
and existing installations in each country, the emissions supply function includes the lower costs of substituting lignite for coal in Germany, and the higher abatement costs of substituting gas for coal (Kirat and Ahamada, 2011). Rightly, as electricity producers who emit more CO2 than their allowances will buy allowances on the market to be in compliance, the carbon price should be added to the fuel and operational costs of electricity generation. On the other hand, due to the free allocation of CO2-emission allowances to participants at the beginning of the period and the emergence of a carbon price from the daily market, these permits are a new liquid asset available to participants, creating an opportunity cost for emission permits which equals their market price (Sijm et al., 2006).

\section{Data and econometric modelling}

\subsection{Data and descriptive analysis of carbon and energy prices}

We use electricity prices in $€ / M W h$ from the day-ahead base load $^{3}$ contracts covering the French and German markets and traded on EPEX Spot exchange. ${ }^{4}$ Day-ahead contracts are traded on a given day for the delivery of electricity one day ahead. The data we use here are of weekday frequency and run from March 3rd, 2008 to December 30th, 2010. Due to its liquidity, the carbon spot price comes from the Bluenext environmental trading exchange expressed in $€$ per ton. With respect to primary energy markets, we appeal to the following price series expressed in $€$ per MWh: i) the gas price of the month-ahead future contract traded on the Zeebrugge hub; and ii) the coal price of the month-ahead future contract Coal CIF ARA. The temperatures variables are calculated as the average temperatures recorded at representative regional weather stations, which are taken from the European Climate Assessment and Dataset. ${ }^{5}$ Our final sample consists of 724 observations, the main characteristics of which are described below.

Figures 1 and 2 show the French and German day-ahead electricity prices, as well as the prices of gas, coal and carbon over the period from March 2008 until December 2010.

These figures show that day-ahead contract prices are very volatile. The price of coal fluctuates within a range of 5 to $20 € / \mathrm{MWh}$ around an average of $10 € / \mathrm{MWh}$. The price of gas experiences two phases. The first covers 2008 and is characterized by significant fluctuations around an average of $25 € / \mathrm{MWh}$, including a sharp increase in the second semester when gas prices rose from just above $27 € / M W h$ in August to around $37 € /$ MWh in October. The second phase covers 2009 and 2010, during which the price of gas fluctuates within a range of 10 to $20 € / \mathrm{MWh}$ with an increasing trend towards the end of the period.

The spot price of carbon fluctuated in the range of 20 to $30 €$ per ton from March 2008 until October

\footnotetext{
${ }^{3}$ The electricity base-load price is the price on the block for 24 hours. This is an arithmetic average price over the 24 hours of the day (from $0 \mathrm{~h}$ to $23 \mathrm{~h}$ ).

${ }^{4}$ EPEX Spot exchange is a holding company created by the cooperation between EEX Power Spot and Powernext SA, the German and French electricity stock exchanges, respectively.

${ }^{5}$ Klein Tank et al., "Daily dataset of 20th-century surface air temperature and precipitation series for the European Climate Assessment", 2011, available at http://eca.knmi.nl.
} 


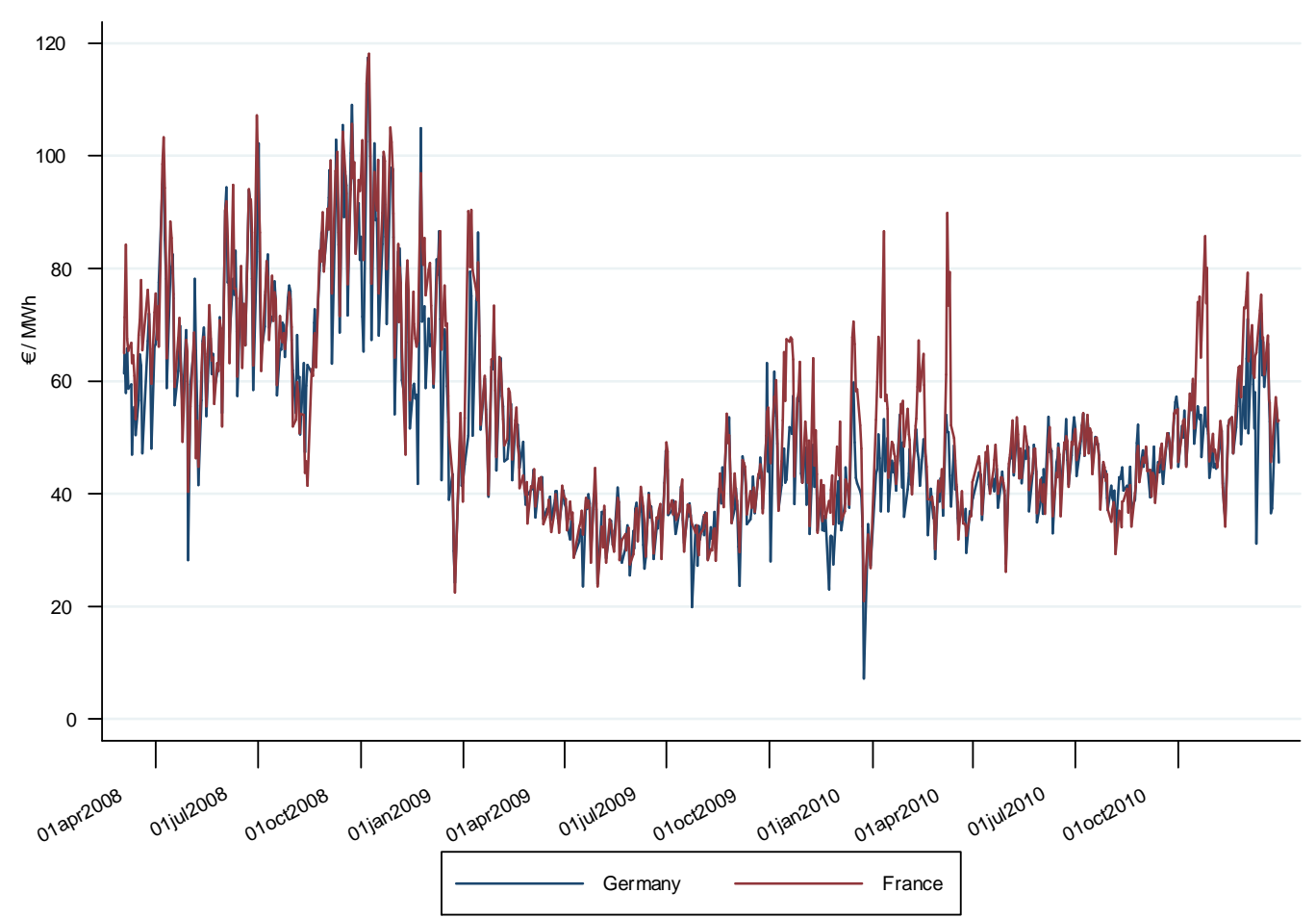

Figure 1: Day-ahead contract electricity prices in France and Germany.

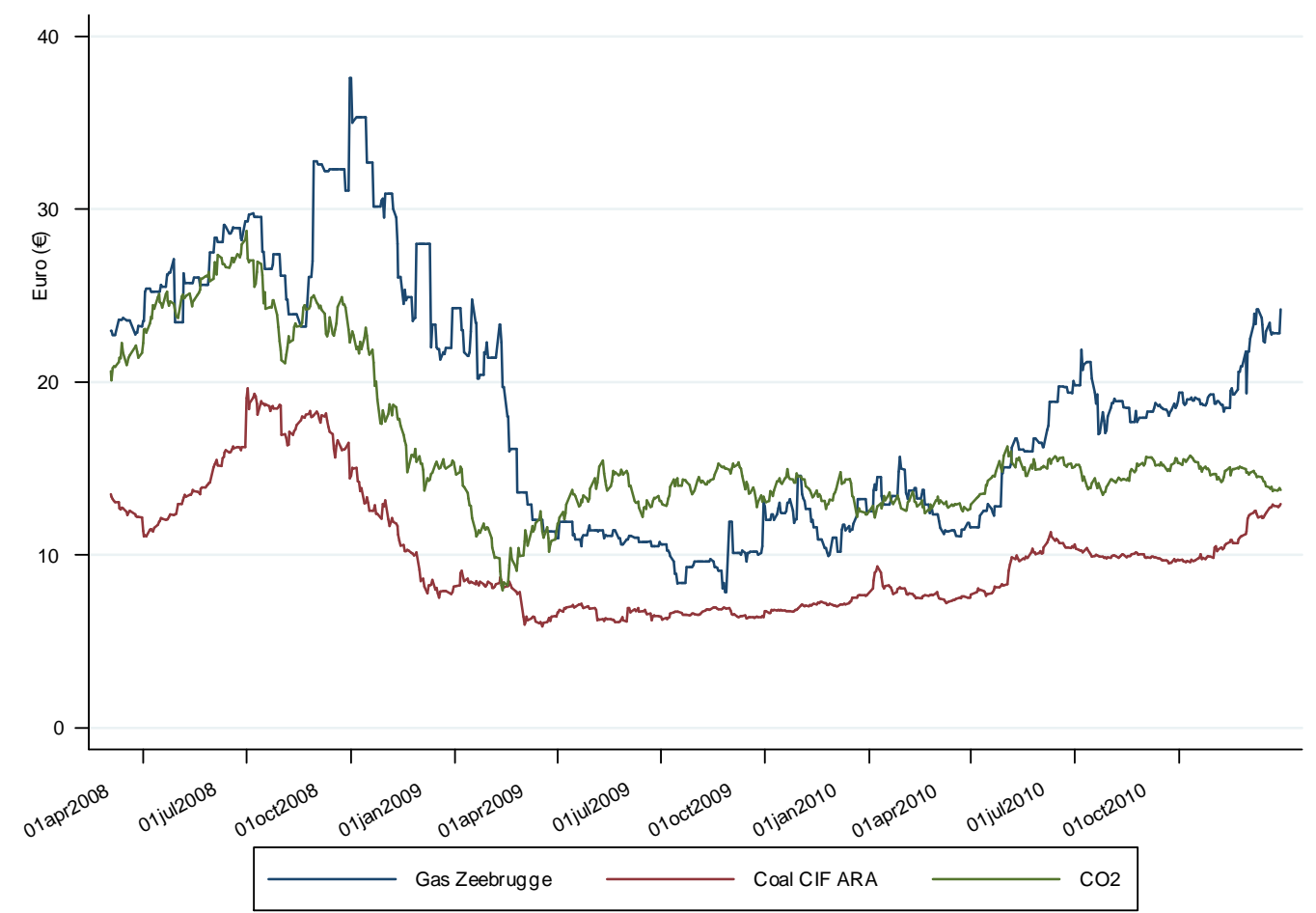

Figure 2: Carbon, gas and coal prices. 


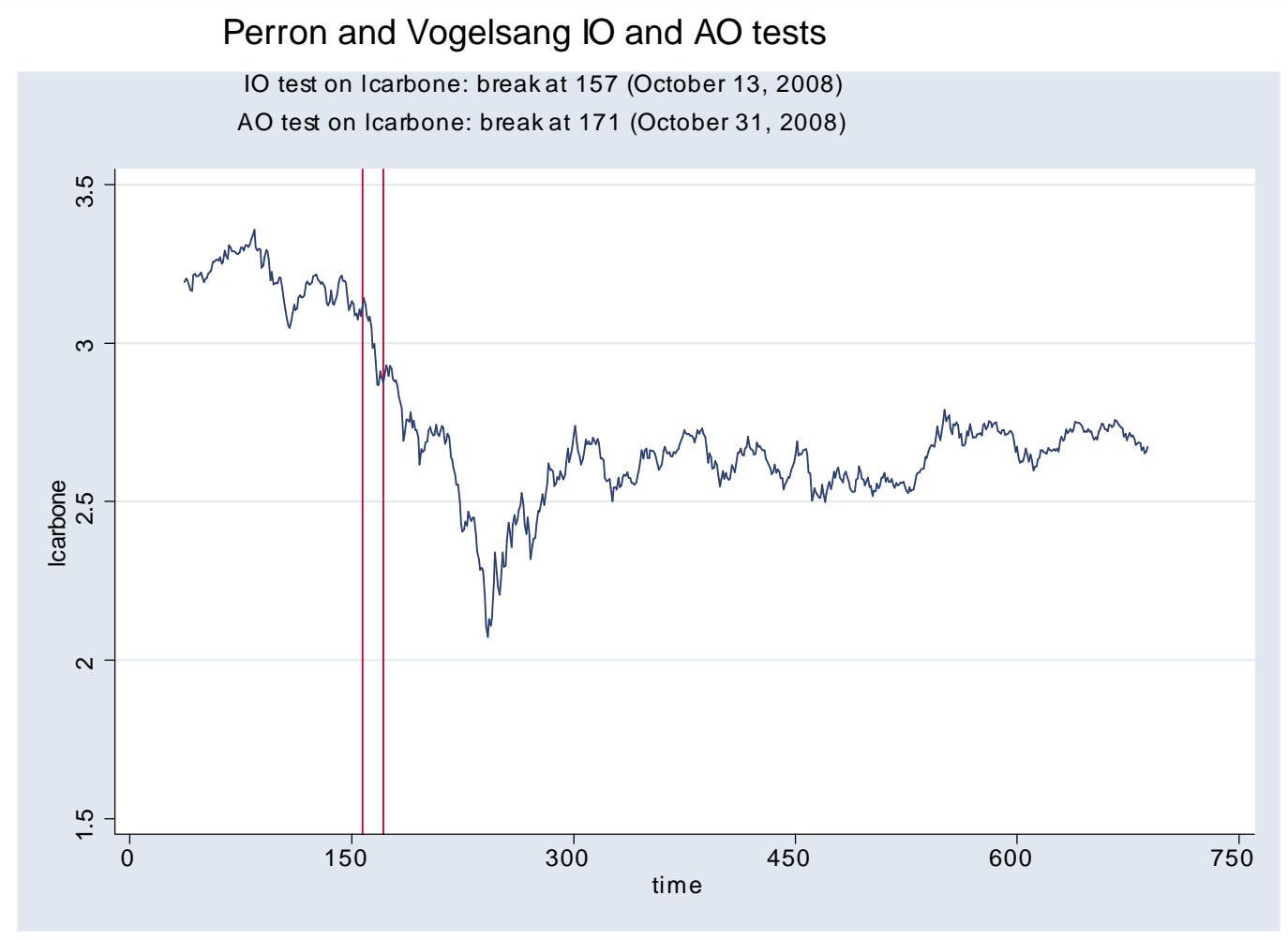

Figure 3: Detection of structural-break dates.

2008, peaking at over $28 €$ on July 1, 2008. From October 2008, the price of CO2 emissions fell below 20 $€$ and declined to go below $8 €$ in February 2009. Then it rose again to hover around a range of $13 €-14$ $€$ until December 2010. The sharp drop in carbon spot price from October 2008 gives a visual feeling of significant break in the carbon spot price series. Following Kirat and Ahamada (2011), we thus apply a unitroot test with structural breaks to detect the break dates in carbon spot prices. We chose the unit-root test with a change in the mean pioneered by Perron and Vogelsang ${ }^{6}$ (1992), where the break date is endogenous. There are two procedures, according to whether the series is detrended or not before performing the unit root test. The procedure consisting in applying a filter before the test is called $A O$ (Additive Outlier) and captures sudden changes in the mean of the series. That which detrends and performs the test at the same time is called IO (Innovational Outlier) and captures incremental changes in the mean of the series. The test findings regarding the break date are summarized in Figure 3.

The test applied to the logarithm of the emission allowance spot price series suggests a structural break. The $I O$ procedure puts this at October 13th, 2008 while the $A O$ procedure puts this at October 31st, 2008. These break dates are very close thus demonstrating the relevance and robustness of the structural-break date. The structural break corresponds to a sharp drop in the carbon spot price, which fell to below $15 €$ per ton. The emission permit loses over a half of its value in less than five months. This collapse in the

\footnotetext{
${ }^{6}$ See the Appendices for more details on this test.
} 
carbon spot price is due to a low demand of emission permits, which in turn can be attributed to several factors. Firstly, the financial crisis and the declining global equity prices followed by the economic crisis caused a reduced economic activity of electricity producers and the major emitters of the industrial sector, which was inevitably followed by a drop in real emissions. Emissions of greenhouse gases from European Union businesses participating in the EU ETS fell by $11.6 \%$ in 2009 compared with 2008. Secondly, the low level of gas prices throughout 2009 made it much more attractive to produce power from gas rather than coal. Economic theory suggests that the price of carbon equals the marginal abatement cost. Assuming that the predominant method of abatement is a shift in the generation dispatch order away from hard coal towards gas (because the former is more than twice as emissions-intensive per unit of output than the latter) we can easily understand that a drop in gas price lowers allowance demand and decreases the permit price.

\subsection{The econometric modeling}

We build on stylized facts by Kirat and Ahamada (2011) to estimate an empirical time-series model. These facts argue that changes in electricity prices reflect changes in the marginal cost of electricity-generation. This includes the cost of the primary energy (gas or coal) used to produce the last unit, operating costs, and carbon costs entering the production of that unit. Temperature is also crucial in determining day-ahead electricity prices. The relationship between electricity demand and temperature is "V-shaped", as electricity demand is higher at both lower and higher temperatures (Engle et al., 1986). To account for the nonlinearity of the relationship between electricity price and temperature, we consider the temperature variable $T$ and its square $T^{2}$.

The econometric specification of the electricity price appeals to dynamic modeling as the price variables are in general functions of expectations formed by agents from their past experiences and new information that they acquire over time. Current period price expectations can then be written as follows:

$$
E\left[P_{t}^{\text {elec }} \mid Z_{t}\right]=g\left(Z_{t}\right)
$$

where $Z_{t}$ represents the information currently available to the agents, such as the price of energy used in electricity generation and past observations of the electricity price. More specifically, we assume that the price of electricity is based on several variables: its past values, the current prices of gas, coal and carbon dioxide emissions, seasonal dummies season $_{i}, i=1,2,3,4,5$ (corresponding to the five business days of the week $j, j=$ Monday, ..., Friday), and the temperature variables $T$ and $T^{2}$. This yields the following equation:

$$
\begin{aligned}
P_{t}^{\text {elec }}= & \alpha_{0}+\sum_{i=1}^{p} \alpha_{i} P_{t-i}^{\text {elec }}+\beta P_{t}^{\text {gas }}+\delta P_{t}^{\text {coal }}+\gamma P_{t}^{\text {carbon }} \\
& +\lambda_{1} T_{t}+\lambda_{2} T_{t}^{2}+\sum_{j=2}^{5} \psi_{j} \text { season }_{j}+\varepsilon_{t}
\end{aligned}
$$


where $P_{t}^{y}$ is the logarithm of the price of commodity $y$ in period $t$. The number of lags $p$ of the dependent variable will be determined for each country by minimizing the Akaike $(A I C)$ or Bayesian $(B I C)$ information criterion. In order to consider the interdependence between the French and German electricity markets and allow time varying conditional correlation matrix, we specify the following model with Dynamic Conditional Correlation (Engle, 2002; Engle and Sheppard, 2001) $\mathrm{DCC}_{E}(1,1)$ errors:

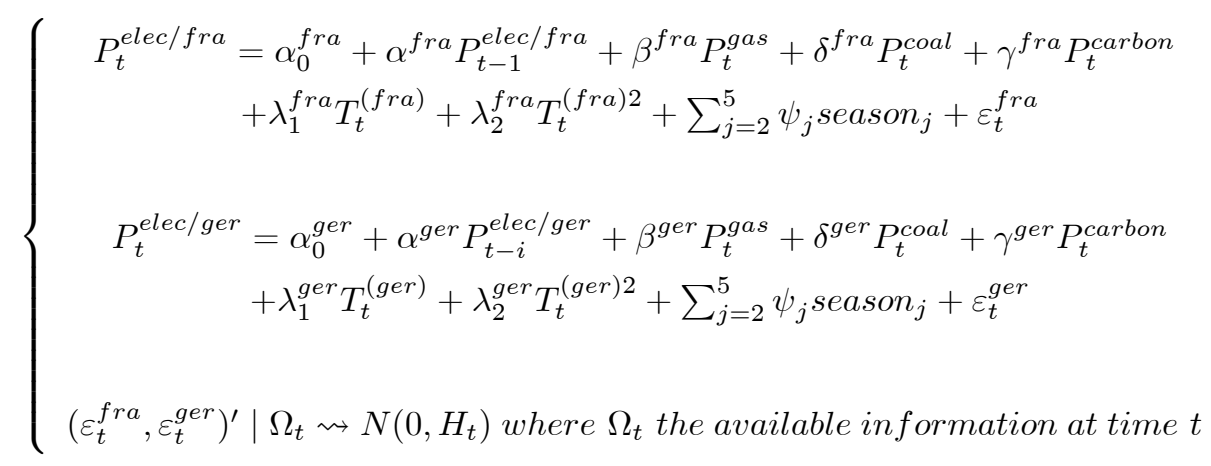

The model $D C C_{E}(1,1)$ is defined as:

$$
\left\{\begin{array}{c}
H_{t}=D_{t} R_{t} D_{t} \\
D_{t}=\operatorname{diag}\left(\sqrt{h_{11 t}}, \sqrt{h_{22 t}}\right) \\
R_{t}=\left(\operatorname{diag} Q_{t}\right)^{1 / 2} Q_{t}\left(\operatorname{diag} Q_{t}\right)^{-1 / 2}
\end{array}\right.
$$

where the $2 \times 2$ symmetric positive definite matrix $Q_{t}$ is given by:

$$
Q_{t}=\left(1-\theta_{1}-\theta_{2}\right) \bar{Q}+\theta_{1} u_{t-1} u_{t-1}^{T}+\theta_{2} Q_{t-1}
$$

Here $u$ is the matrix of standardized residuals, $\bar{Q}$ is the $2 \times 2$ unconditional variance matrix of $u_{t}$, and $\theta_{1}$ and $\theta_{2}$ are non-negative parameters satisfying $\theta_{1}+\theta_{2}<1$. The $D C C(1,1)$ model is estimated in two steps. ${ }^{7}$ First, the conditional variance of electricity prices in France and Germany are estimated from a $G A R C H(1,1)$ and $A R C H(1)$ specifications, respectively, at the same time as the conditional-mean equation. The standardized residuals are then used to model the correlation in an autoregressive manner to obtain the time-varying conditional correlation matrix. The conditional variance-covariance matrix $H_{t}$ is the product of the diagonal matrix of the conditional standard deviation $D_{t}$ with the conditional correlation matrix $R_{t}$ and the matrix $D_{t}$ again. The $R_{t}=\left(\begin{array}{ll}1 & \rho_{12 t} \\ \rho_{21 t} & 1\end{array}\right)$ matrix reflects the instantaneous conditional correlation between day-ahead electricity contract prices on the French and German power exchanges. The estimation results for these models are presented in Table 1 and Figure 5.

We do indeed estimate a long-run relationship between the electricity price and its fundamentals, based on average correlations over the entire March 3rd 2008 to December 30th 2010 period. However, the structural break in carbon spot prices, detected with the Perron-Vogelsang test using the $I O$ and/or $A O$ procedure, may affect the relationship between the price of carbon and that of electricity and its fundamentals. To see

\footnotetext{
${ }^{7}$ See the Appendices for more details regarding model estimation.
} 
whether this is the case, we test the stability of the whole estimated coefficients using Chow test. We test the equality of the estimated coefficients for the periods before and after October 13th 2008, and then for the periods before and after October 31st, 2008. The results of these stability tests suggest that: i) the longrun relationship between the price of electricity, fossil-fuel prices and the carbon spot price is unstable over the whole period; and ii) this relationship changed after October 2008 in both countries. We thus compare estimated models of electricity prices over two sub-periods: before and after the structural break. Depending on whether the break date considered is detected using the $I O$ or $A O$ tests, the estimation results include four sub-periods: March 3rd 2008 to October 13th 2008, March 3rd 2008 to October 31st 2008, October 14th 2008 to December 30th 2010 and November 1st 2008 till December 30th 2010. The next section interprets the results.

\section{Results and interpretation}

The results in table 1 refer to the estimated prices of German and French electricity day-ahead contracts, both over the entire period from March 3rd 2008 to December 30th 2010 and in shorter sub-periods. Fullperiod results are given in columns (2) and (7) to illustrate the non-relevancy of inference when omitting nonlinearity. Sub-period results are given for two sets of sub-periods. Each set includes sub-periods in relation with the structural break in the carbon spot price detected using $I O$ and $A O$ procedures, respectively. The break dates and the estimation results over the sub-periods of both sets are very close. This proves the robustness of our results.

Before going into the details of the results in table 1 , it is worth considering their general aspects. Over the sub-periods, all of the estimated coefficients which are significant at the $5 \%$ level have the expected sign. The estimated coefficients on log prices are interpreted as long-run elasticities, as the models reflect longrun relationships. The significant estimated coefficients on lagged electricity prices reflect the dependence between contemporary electricity prices and those in previous periods: this dependence comes from the expectations of contemporary electricity prices held by agents in previous periods. We note that electricity prices in both countries vary by day of the week; weekday prices are lower.

We first focus on the sub-periods results and look at the conditional correlation between electricity markets. Then, we discuss the impact of the EU ETS on the electricity-generation sector and compare the results with those of the pilot phase reported in Kirat and Ahamada (2011).

\subsection{Electricity-price estimation results over the sub-periods March 2008 - Oc- tober 2008 and October 2008 - December 2010}

Over the sub-period March 2008 - October 2008, the results suggest that temperatures do not affect electricity

prices in Germany. On the contrary, the estimated coefficients on $T$ and $T^{2}$ show that milder temperatures push the day-ahead contract price in France downwards, and that variations in temperatures towards extreme 
Table 1. Electricity Contract Price Estimation Results

\begin{tabular}{|c|c|c|c|c|c|c|c|c|c|c|}
\hline Country & \multicolumn{5}{|c|}{ Germany } & \multicolumn{5}{|c|}{ France } \\
\hline \multirow{4}{*}{$\begin{array}{l}\text { period } \\
\text { break date }\end{array}$} & Full period & \multirow{2}{*}{\multicolumn{2}{|c|}{$\begin{array}{l}\text { sub-periods }(I O) \\
\text { October } 13,2008\end{array}$}} & \multirow{2}{*}{\multicolumn{2}{|c|}{$\begin{array}{l}\text { sub-periods }(A O) \\
\text { October } 31,2008\end{array}$}} & Full period & \multirow{2}{*}{\multicolumn{2}{|c|}{$\begin{array}{l}\text { sub-periods }(I O) \\
\text { October } 13,2008\end{array}$}} & \multirow{2}{*}{\multicolumn{2}{|c|}{$\begin{array}{l}\text { sub-periods }(A O) \\
\text { October } 31,2008\end{array}$}} \\
\hline & & & & & & & & & & \\
\hline & & Before & After & Before & After & & Before & After & Before & After \\
\hline & & break & break & break & break & & break & break & break & break \\
\hline \multicolumn{11}{|c|}{ Mean equation } \\
\hline \multirow[t]{2}{*}{$P_{t-1}^{\text {elec }}$} & $0.672^{* * *}$ & $0.597^{* * *}$ & $0.652^{* * *}$ & $0.621^{* * *}$ & $0.644^{* * *}$ & $0.743^{* * *}$ & $0.585^{* * *}$ & $0.709 * * *$ & $0.622^{* * *}$ & $0.688^{* * *}$ \\
\hline & $(0.029)$ & $(0.098)$ & $(0.032)$ & $(0.098)$ & $(0.036)$ & $(0.026)$ & $(0.095)$ & $(0.031)$ & $(0.089)$ & $(0.032)$ \\
\hline \multirow[t]{2}{*}{$P_{t}^{g a s}$} & $0.172^{* * *}$ & $0.439 * * *$ & $0.189 * * *$ & $0.399^{* * *}$ & $0.187^{* * *}$ & $0.114^{* * *}$ & $0.602^{* * *}$ & $0.125^{* * *}$ & $0.530 * * *$ & $0.121^{* * *}$ \\
\hline & $(0.028)$ & $(0.112)$ & $(0.032)$ & $(0.115)$ & $(0.034)$ & $(0.028)$ & $(0.161)$ & $(0.032)$ & $(0.154)$ & $(0.032)$ \\
\hline \multirow[t]{2}{*}{$P_{t}^{c o a l}$} & $-0.067^{* *}$ & -0.021 & $-0.094^{* *}$ & -0.041 & $-0.086^{* *}$ & -0.049 & -0.005 & -0.076 & -0.032 & -0.063 \\
\hline & $(0.033)$ & $(0.096)$ & $(0.041)$ & $(0.091)$ & $(0.041)$ & $(0.038)$ & $(0.102)$ & $(0.046)$ & $(0.093)$ & $(0.046)$ \\
\hline \multirow[t]{2}{*}{$P_{t}^{\text {carbon }}$} & $0.181^{* * *}$ & $0.226^{*}$ & $0.139 * * *$ & 0.142 & $0.129^{* * *}$ & $0.188^{* * *}$ & 0.191 & $0.216^{* * *}$ & 0.128 & $0.193^{* * *}$ \\
\hline & $(0.032)$ & $(0.136)$ & $(0.043)$ & $(0.109)$ & $(0.043)$ & $(0.031)$ & $(0.132)$ & $(0.044)$ & $(0.101)$ & $(0.045)$ \\
\hline \multirow[t]{2}{*}{$T^{l e v e l}$} & $-0.005^{* * *}$ & -0.012 & $-0.005^{* * *}$ & -0.007 & $-0.005 * * *$ & $-0.015^{* * *}$ & $-0.039 * * *$ & $-0.017^{* * *}$ & $-0.029^{* *}$ & $-0.020 * * *$ \\
\hline & $(0.001)$ & $(0.009)$ & $(0.001)$ & $(0.009)$ & $(0.001)$ & $(0.002)$ & $(0.012)$ & $(0.002)$ & $(0.012)$ & $(0.003)$ \\
\hline \multirow[t]{2}{*}{$\left(T^{\text {level }}\right)^{2}$} & $0.0001^{* *}$ & 0.0004 & $0.0001^{* *}$ & 0.0002 & $0.0001^{* *}$ & $0.0004^{* * *}$ & $0.001^{* * *}$ & $0.000 * * *$ & $0.001^{* *}$ & $0.0005^{* * *}$ \\
\hline & $(0.000)$ & $(0.0003)$ & $(0.000)$ & $(0.000)$ & $(0.000)$ & $(0.000)$ & $(0.000)$ & $(0.000)$ & $(0.000)$ & $(0.000)$ \\
\hline \multirow[t]{2}{*}{ cons } & $0.606^{* * *}$ & -0.174 & $0.801^{* * *}$ & 0.163 & $0.847^{* * *}$ & $0.538^{* * *}$ & -0.314 & $0.628^{* * *}$ & -0.034 & $0.759^{* * *}$ \\
\hline & $(0.059)$ & $(0.518)$ & $(0.103)$ & $(0.462)$ & $(0.121)$ & $(0.061)$ & $(0.501)$ & $(0.090)$ & $(0.442)$ & $(0.103)$ \\
\hline season $_{2}$ & $-0.128^{* * *}$ & $-0.074^{* *}$ & $-0.134^{* * *}$ & $-0.089 * * *$ & $-0.134^{* * *}$ & $0.151^{* * *}$ & $-0.166^{* * *}$ & $-0.132^{* * *}$ & $-0.172^{* * *}$ & $-0.129 * * *$ \\
\hline season $_{3}$ & $-0.103^{* * *}$ & $-0.119^{* * *}$ & $-0.094^{* * *}$ & $-0.135 * * *$ & $-0.094^{* * *}$ & $0.149 * * *$ & $-0.173^{* * *}$ & $-0.127^{* * *}$ & $-0.183^{* * *}$ & $-0.122 * * *$ \\
\hline season $_{4}$ & $-0.171^{* * *}$ & $-0.192 * * *$ & $-0.156 * * *$ & $-0.212^{* * *}$ & $-0.153^{* * *}$ & $0.174^{* * *}$ & $-0.197 * * *$ & $-0.154^{* * *}$ & $-0.205^{* * *} *$ & $-0.150 * * *$ \\
\hline season $_{5}$ & $-0.308 * * *$ & $-0.315 * * *$ & $-0.301^{* * *}$ & $-0.346 * * *$ & $0.297^{* * *}$ & $0.303^{* * *}$ & $-0.343^{* * *}$ & $-0.282 * * *$ & $-0.357^{* * *}$ & $-0.278^{* * *}$ \\
\hline \multicolumn{11}{|c|}{ Conditional variance equation } \\
\hline cons & $0.008^{* * *}$ & $0.010 * * *$ & $0.007^{* * *}$ & $0.010 * * *$ & $0.007^{* * *}$ & $0.002^{* * *}$ & 0.003 & $0.002^{* * *}$ & 0.003 & $0.002^{* * *}$ \\
\hline$A R C H$ & $0.793^{* * *}$ & $0.487 * *$ & $0.877^{* * *}$ & $0.448^{* * *}$ & $0.877^{* * *}$ & $0.227^{* * *}$ & 0.104 & $0.249 * * *$ & 0.102 & $0.245^{* * *}$ \\
\hline$G A R C H$ & & & & & & $0.557 * * *$ & $0.580^{* *}$ & $0.608^{* * *}$ & $0.580^{* *}$ & $0.628^{* * *}$ \\
\hline$L L$ & 501.72 & 107.54 & 409.06 & 118.36 & 401.59 & 604.54 & 137.54 & 486.01 & 150.87 & 477.94 \\
\hline
\end{tabular}

Standard errors are in (); ${ }^{*},{ }^{* *}$ and ${ }^{* * *}$ refer respectively to the $10 \%, 5 \%$ and $1 \%$ significance levels. IO and $A O$ refer to the procedure used in the Perron-Vogelsang test which determines the break dates and the corresponding sub-periods 

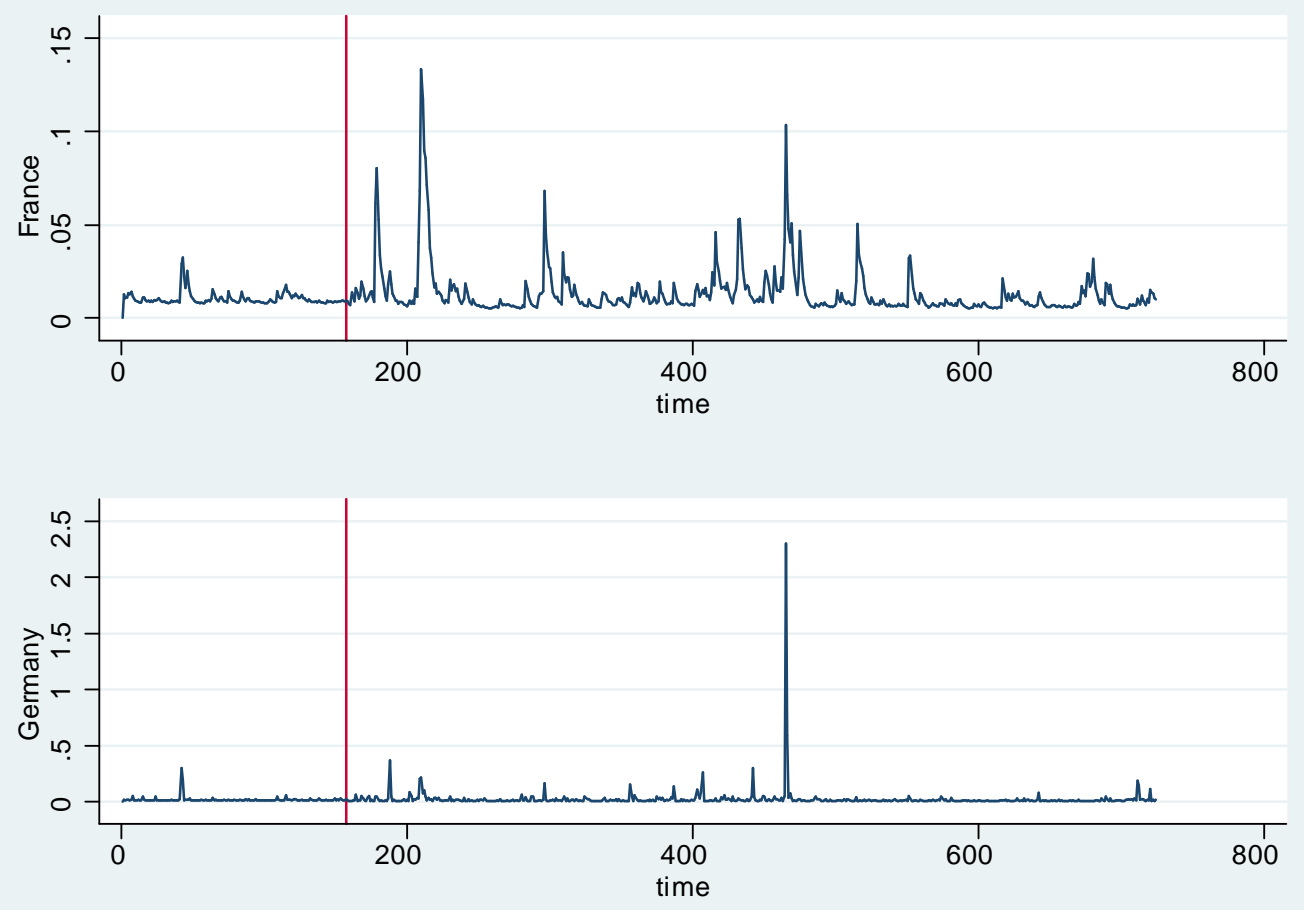

Figure 4: Conditional variances of French and German electricity prices in the case of $I O$ break in the carbon spot price series

values lead to higher prices. Over this sub-period, only the price of gas affects electricity prices in the longrun equilibrium. All else equal, a $1 \%$ higher gas price leads to a rise of $0.53 \%$ to $0.60 \%$ and $0.40 \%$ to $0.44 \%$ in the French and German day-ahead prices, respectively. The elasticity of the electricity price relative to the gas price is slightly higher for France than for Germany. The price of carbon does not matter for electricity prices in both countries.

Over the sub-period October 2008 - December 2010, temperatures affect electricity prices in both countries. Milder temperatures push electricity prices downwards, and variations in temperatures towards extreme values lead to higher prices. Over this period, estimation results of the mean equations highlight significant differences between countries in the way in which primary energies and carbon appear in the electricity-generation cost function. In France, the price of gas, unlike that of coal, determines the price of electricity: $1 \%$ higher gas prices result in $0.12 \%$ higher electricity prices. In contrast, in Germany, both gas and coal prices determine the price of electricity: $1 \%$ higher gas prices result in $0.19 \%$ higher electricity prices and $1 \%$ higher coal prices result in $0.09 \%$ lower electricity prices. The impact of gas price and coal price on German electricity price are of opposite signs. This result is consistent with a trade-off between gas and coal in producing electricity in Germany. The elasticities of electricity prices relative to gas prices 


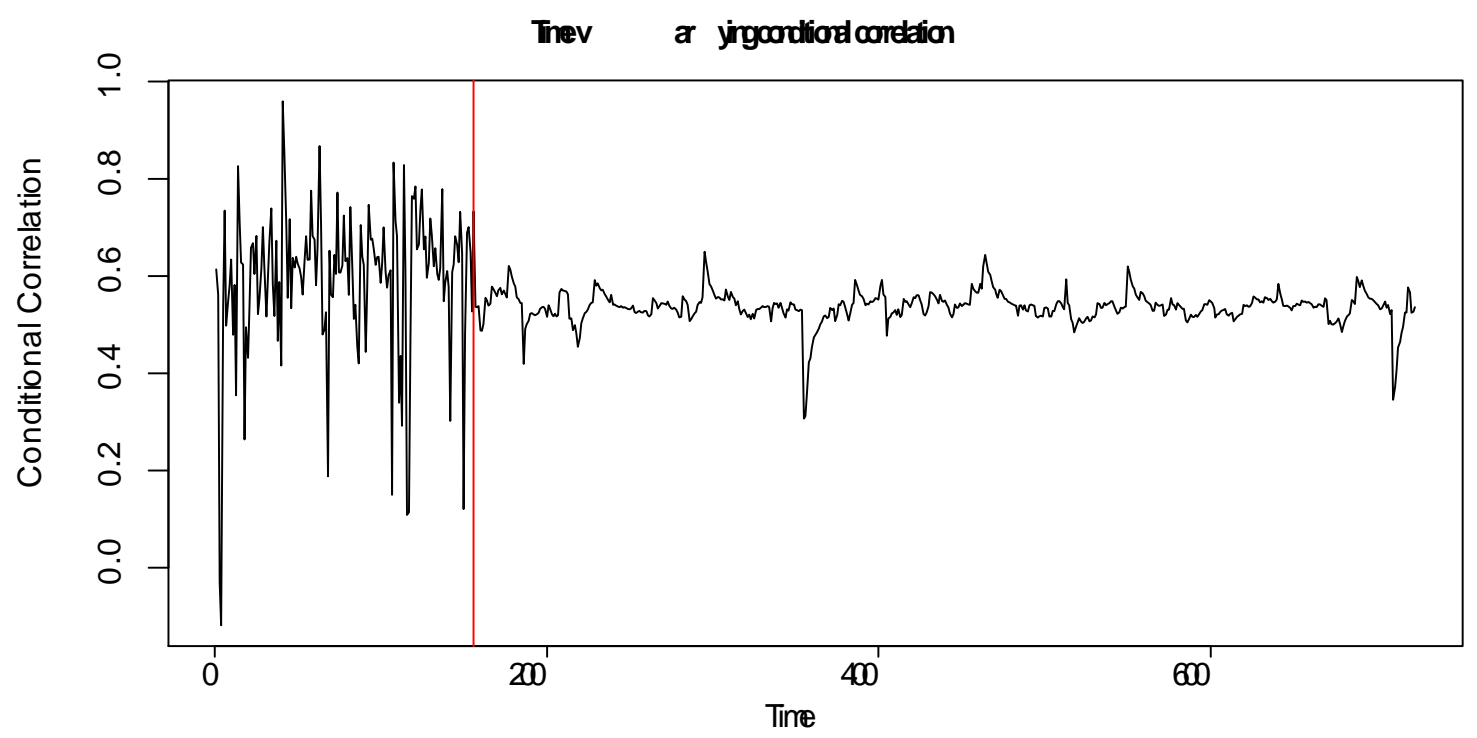

Figure 5: Conditional correlation of French and German electricity prices in the case of $I O$ break in the carbon spot price series.

are lower during this sub-period than over the previous. The price of carbon strongly affects the price of electricity in both countries. A rise of $1 \%$ in the emission-permit price results in $0.19 \%$ to $0.21 \%$ and $0.13 \%$ to $0.14 \%$ higher French and German electricity prices, respectively.

The carbon spot price did help to determine electricity prices only over the sub-period after October 2008. The elasticity of the electricity price relative to the carbon-allowance spot price is higher in France than in Germany. This may seems counter-intuitive, given the national energy mixes of both countries. However, the reduction of carbon allowances during the second phase of the EU ETS and the evidence of a trade-off between gas and coal in electricity-generation in Germany helps to clarify the result. Since the abatement method of choice in the electricity-generation sector is a production shift from coal to gas, German producers have more opportunities to reduce their emissions than their French counterparts.

The estimates of the conditional variance equations over both sub-periods suggest that electricity price variations in the German and French day-ahead contracts are volatile. Electricity price volatilities are higher over the second sub-period compared with the first sub-period. For each country, the sum of the $A R C H$ and/or GARCH coefficients is greater over the second sub-period than over the first one. Figures 4 and 6 show the conditional variances of electricity prices in France and Germany and are consistent with a higher volatility over the second sub-period than over the first sub-period. Over the second sub-period, the sum of the $A R C H$ and/or $G A R C H$ coefficients are equal in France and Germany. So is the variance of the electricity price around its fundamentals. The return to the long-run equilibrium path following a deviation in the day-ahead contract price and reflecting an over- or under-estimation of the price of carbon by electricity producers, is as fast in Germany as in France. 

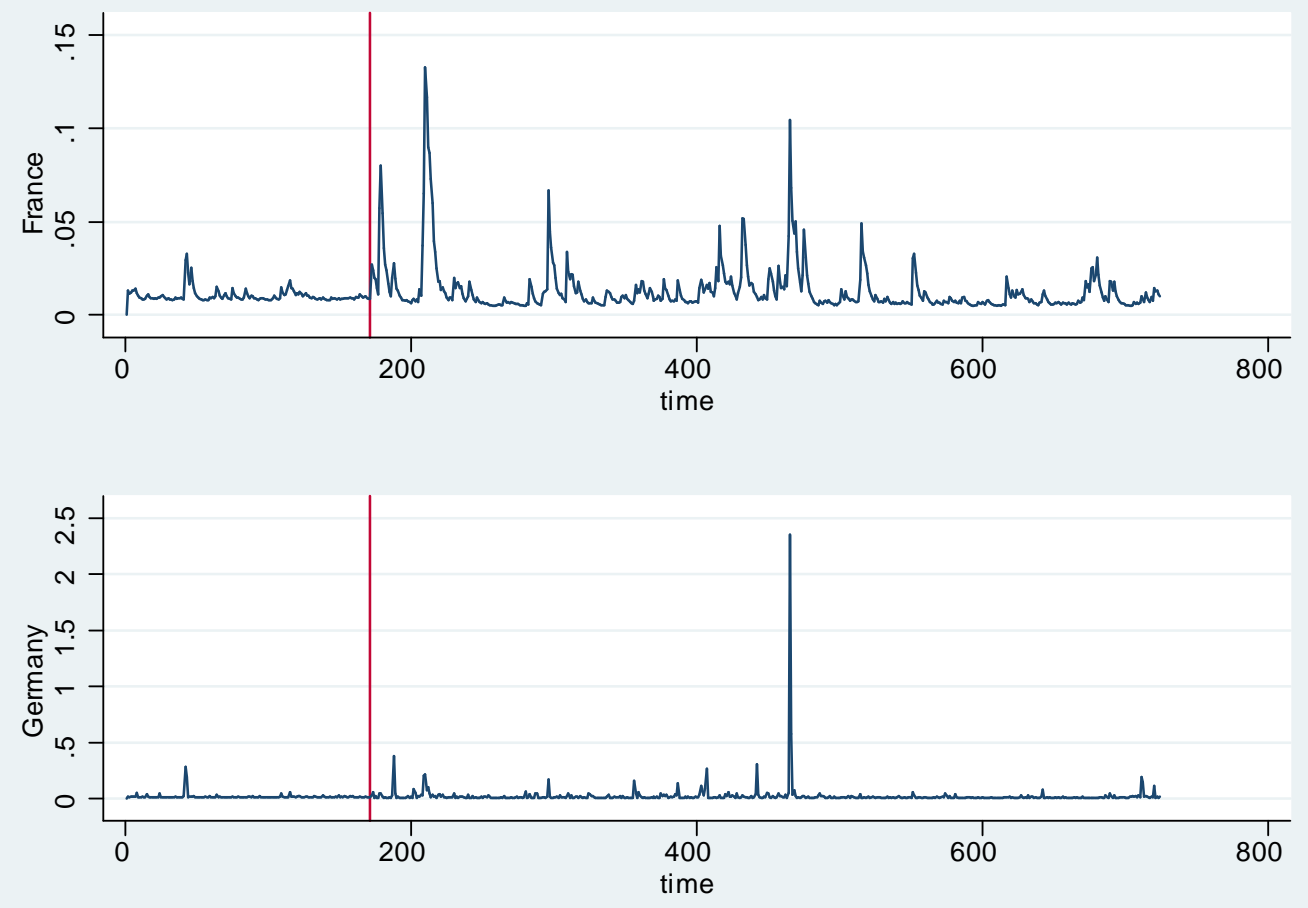

Figure 6: Conditional variances of French and German electricity prices in the case of $A O$ break in the carbon spot price series.

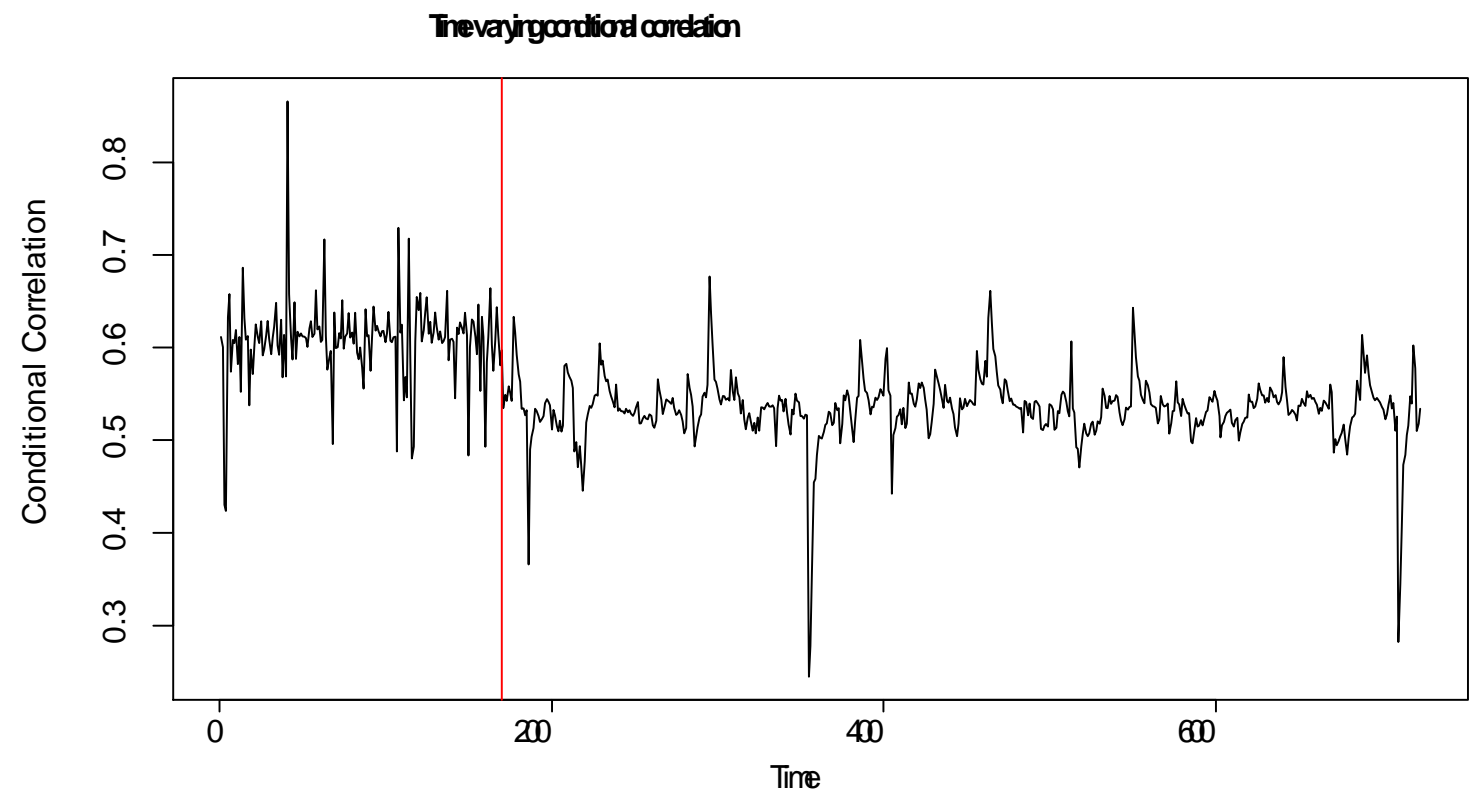

Figure 7: Conditional correlation of French and German electricity prices in the case of $A O$ break in the carbon spot price series. 
Figures 5 and 7 depicts the dynamics of the conditional correlation between the prices of day-ahead electricity contracts in France and Germany. These correlations are positive and highly significant. It was very volatile around a value of around 0.6 in the first sub-period up to October 2008. Thereafter, it became slightly less volatile and vary around a value of 0.55 .

\subsection{Discussion}

Now, let us compare estimation results over the sub-period October 2008 - December 2010 (phase 2) with those reported by Kirat and Ahamada (2011) concerning the period July 2005 - December 2006 (pilot phase). The differences reflect mainly the impact of the possibility of "banking" carbon permits to subsequent periods and the reduction of the allowance cap. The elasticity of the electricity price relative to the price of carbon permit is higher over the second phase of the EU ETS than over the pilot phase in both countries. In France, this elasticity has tripled between the two periods while it has been multiplied by 1.5 in Germany. However, unlike the pilot phase of the EU ETS, German electricity producers were less constrained by the EU ETS than their French counterparts. Electricity prices in both countries were much more strongly correlated during the second phase of the EU ETS than over the pilot phase. The conditional correlation were dynamic and varied over time in the second phase while it was constant in the pilot phase. During its pilot phase, the carbon market allowed the French electricity producers to extract more profits from their productive park. It was not the case during the second phase of the EU ETS, thanks to lower allocations in the national allocation plans (NAPs).

Overall, the results here show that the European market for emission allowances did have an impact on the power-generation sector in both countries. The conclusion regarding the impact of improvements to the EU ETS during its second phase on the electricity-generation sectors can be summarized as follows: it is possible to apply for the same abatement effort to electricity producers of different European countries, even with heterogeneous energy mixes, by merely adjusting the ceiling of carbon permits granted to each of them.

\section{Conclusion}

In this paper we have estimated the relationship between electricity prices, the prices of primary energies used in electricity generation and the price of carbon dioxide emission permits, in both France and Germany, over the second phase of the EU ETS. We have shown that the impact of the carbon market during the Kyoto commitment period on electricity-generation sector was felt in two phases. The first covers the first ten months of the second phase of the EU ETS, during which the carbon constraint did not affect electricity producers' decisions; the second covers years 2009 and 2010 during which electricity producers included the cost of carbon in their production cost function. We have also compared the results with those reported in Kirat and Ahamada (2011) concerning the pilot phase of the EU ETS. This revealed improvements in the responses of the electricity-generation sectors to carbon constraints. The impact of carbon price on 
electricity prices increased by $300 \%$ and $150 \%$ in France and Germany, respectively. The introduction of "banking" in the EU ETS and the reduction in the largesse granted by the national authorities of European countries to their power-generation sectors during the pilot phase increased significantly the efficiency of the EU ETS.

\section{A APPENDICES}

\section{A.1 The Perron-Vogelsang test}

The Perron-Vogelsang (1992) test with a change in the mean using the $A O$ procedure implemented on a series $y$ is based on the estimation of the following equation:

$$
y_{t}=\mu+\delta D U_{t}+\widetilde{y_{t}}
$$

Here $D U_{t}=1$ for $t \succ T_{b}$ and 0 otherwise. $T_{b}$ is the date of the structural break and will be identified by the scan method. The noise from this equation is the dependent variable in the following equation:

$$
\widetilde{y_{t}}=\sum_{i=1}^{k} \omega_{i} D T_{b, t-i}+\rho \widetilde{y_{t-1}}+\sum_{i=1}^{k} \theta_{i} \Delta \widetilde{y_{t-i}}+e_{t}
$$

Here $D T_{b, t}=1$ for $t=T_{b}+1$ and 0 otherwise. This equation is estimated for each date $T_{b}$ to identify the smallest t-statistic for the unit-root hypothesis, which is then compared with the values tabulated by Perron Vogelsang. In addition, the same test applied to the $y_{t}$ series using the $I O$ procedure is based on the estimation of the following equation:

$$
y_{t}=\mu+\delta D U_{t}+\varphi D T_{b, t}+\rho y_{t-1}+\sum_{i=1}^{k} \theta_{i} \Delta y_{t-i}+e_{t}
$$

Testing the unit root hypothesis is equivalent to testing whether the coefficient $\rho$ is significantly less than 1.

\section{A.2 Two-step estimation of $\mathrm{DCC}_{E}$ models}

The estimation of the parameters of multivariate models is based on the maximum-likelihood method. With Gaussian residuals, the likelihood function is:

$$
L_{T}=\sum_{t=1}^{T} \log f\left(y_{t} \mid \theta, \eta, I_{t-1}\right)
$$

Here $f\left(y_{t} \mid \theta, \eta, I_{t-1}\right)=\left|H_{t}\right|^{-\frac{1}{2}} g\left(H_{t}^{-\frac{1}{2}}\left(y_{t}-\mu_{t}\right)\right)$, the density function of $y_{t}$ given the parameter vector $\theta$ and $\eta$. We assume that $\left(y_{t}-\mu_{t}\right) \rightsquigarrow N\left(0, I_{N}\right)$. Thus, the log-likelihood function is:

$$
L_{T}(\theta)=-\frac{1}{2} \sum_{t=1}^{T}\left[\log \left|H_{t}\right|+\left(y_{t}-\mu_{t}\right)^{\prime} H_{t}^{-1}\left(y_{t}-\mu_{t}\right)\right]
$$


The Gaussian likelihood provides a consistent quasi-likelihood estimator, even if the true density is not Gaussian. In the case of a DCC model the log-likelihood consists of two parts. The first depends on the volatility parameters and the second on the parameters of the conditional correlations given the volatility parameters. So, with $H_{t}=D_{t} R_{t} D_{t}$ we have:

$$
L_{T}(\theta)=-\frac{1}{2} \sum_{t=1}^{T}\left[\log \left|D_{t} R_{t} D_{t}\right|+u_{t}^{\prime} R_{t}^{-1} u_{t}\right]
$$

where $u_{t}=D_{t}^{-1}\left(y_{t}-\mu_{t}\right)$ and $u_{t}^{\prime} R_{t}^{-1} u_{t}=\left(y_{t}-\mu_{t}\right)^{\prime} D_{t}^{-1} R_{t}^{-1} D_{t}^{-1}\left(y_{t}-\mu_{t}\right)$. With this notation, the log-likelihood is:

$$
\begin{gathered}
L_{T}(\theta)=-\frac{1}{2} \sum_{t=1}^{T}\left[\log \left|D_{t} R_{t} D_{t}\right|+u_{t}^{\prime} R_{t}^{-1} u_{t}\right] \\
L_{T}(\theta)=\underbrace{-\frac{1}{2} \sum_{t=1}^{T}\left[2 \log \left|D_{t}\right|+u_{t}^{\prime} u_{t}\right]}_{Q 1 L_{T}\left(\theta_{1}^{*}\right)}-\underbrace{\frac{1}{2} \sum_{t=1}^{T}\left[\log \left|R_{t}\right|+u_{t}^{\prime} R_{t}^{-1} u_{t}-u_{t}^{\prime} u_{t}\right]}_{Q 2 L_{T}\left(\theta_{1}^{*}, \theta_{2}^{*}\right)}
\end{gathered}
$$

with $\theta_{1}^{*}$ being the parameters of the conditional variance $D_{t}$ and $\theta_{2}^{*}$ those of the conditional correlation $R_{t}$. The log-likelihood function can then be written as follows:

$$
L_{T}(\theta)=Q 1 L_{T}\left(\theta_{1}^{*}\right)+Q 2 L_{T}\left(\theta_{1}^{*}, \theta_{2}^{*}\right)
$$

The coefficients $\left(\theta_{1}^{*}, \theta_{2}^{*}\right)$ are estimated in two stages. In the first stage we estimate $\theta_{1}^{*}=\arg \max Q 1 L_{T}\left(\theta_{1}^{*}\right)$ and in the second we estimate $\theta_{2}^{*}=\arg \max Q 2 L_{T}\left(\theta_{1}^{*}, \theta_{2}^{*}\right)$.

\section{References}

[1] Bunn DW, Fezzi C. A vector error correction model of the interactions among gas, electricity and carbon prices: an application to the cases of Germany and United Kingdom, in: F. Gulli (Ed.), Markets for Carbon and Power Pricing in Europe: Theoretical Issues and Empirical Analyses, Edward Elgar Publishing, 2008, pp. 145-159.

[2] Engle RF. Dynamic Conditional Correlation: A Simple Class of Multivariate Generalized Autoregressive Conditional Heteroskedasticity Models. Journal of Business and Economic Statistics, 2002, 20, 339-350.

[3] Engle RF, Granger CWJ, Rice J, Weiss A. Semiparametric Estimates of the Relation Between Weather and Electricity Sales. Journal of the American Statistical Association 1986, 394, 310-320.

[4] Engle RF, Sheppard K. Theoretical and Empirical Properties of Dynamic Conditional Correlation Multivariate GARCH. Stern Finance Working Paper Series 2001, \{FIN\}-01-027, New York University Stern School of Business. 
[5] Honkatukia J, Mälkönen V, Perrels A. Impacts Of The European Emission Trade System On Finnish Wholesale Electricity Prices. in: F. Gulli (Ed.), Markets for Carbon and Power Pricing in Europe: Theoretical Issues and Empirical Analyses, Edward Elgar Publishing, 2008, pp. 160-192.

[6] Kirat D, Ahamada I. The impact of the European Union emission trading scheme on the electricitygeneration sector, Energy Economics, 2011, 33, pp. 995-1003.

[7] Perron P, Vogelsang T. Nonstationarity and level shifts with an application to purchasing power parity. Journal of Business and Economic Statistics, 1992, 10, 301-320.

[8] Sijm JPM, Chen Y, Bakker SJA, Harmsen H, Lise W. CO2 price dynamics: the implications of EU emissions trading for the price of electricity. ECN report 2005, No. ECN-C-05-081.

[9] Sijm JPM, Chen Y, Donkelaar M, Hers JS, Scheepers MJJ. CO2 price dynamics: a follow-up analysis of the implications of EU emissions trading for the price of electricity. ECN report 2006, No. ECN-C-06-015. 